\title{
Health professional education as community development: A case report of lessons learned in rural Canada
}

\author{
Hope N Bilinski ${ }^{1}$, Lois E Berry ${ }^{1}$, Amy L Wright ${ }^{1,2}$ \\ 1. College of Nursing, University of Saskatchewan, Saskatoon, Canada. 2. School of Nursing, McMaster University, \\ Hamilton, Canada.
}

Correspondence: Hope Bilinski. Address: College of Nursing, University of Saskatchewan, 104 Clinic Place, Health Sciences Building, Saskatoon SK, Canada. Email: hope.bilinski@usask.ca

Received: April 22, 2013

DOI : $10.5430 /$ jnep.v4n2p20
Accepted: July 16, 2013

URL: http://dx.doi.org/10.5430/jnep.v4n2p20

\section{Abstract}

The placement of nursing students in rural settings has a number of advantages. The exposure to rural practice provides opportunities for students to enhance their knowledge and challenge their perceptions relating to the unique characteristics of rural health and rural practice. In addition, students who take part in rural clinical placements are more likely to seek employment in these settings thus potentially contributing to recruitment of nurses for rural areas. There are limited reports on the development of effective and sustainable partnerships between rural communities and educational institutions. These partnerships can be innovative solutions for meeting the needs of educational institutions and rural communities.

The Community Based Capacity Building Model for Nursing Education was developed to illustrate the four phases that are essential for productive community partnerships that can be utilized in nursing education. The four phases of relationship building, discovery, mentoring, and support are important components in the overall process and contribute signifycantly to the success in building and sustaining capacity for rural educational experiences. Each partner has a considerable role to play in each phase of the model. The overall aim is to utilize the strengths of the academic partner and the unique knowledge and expertise of rural nurses in the education of nursing students.

The Community Based Capacity Building Model provides a valuable framework for working with rural communities. The outcomes of progressing through the phases of the model include the shared commitment to the education of nursing students, the realization of the mutual benefits of the partnership, and the development of a sustainable partnership that supports the inclusion of rural clinical experiences for nursing students. Lessons learned included the emphasis placed on mutual understanding, recognition, and respect and the acknowledgement of the challenges inherent in rural settings and how these challenges impact rural clinical placements.

\section{Key words}

Community partnership, Rural, Capacity building

\section{Introduction}

Educational facilities have initiated rural placements for nursing students in order to enhance student's understanding of rural health, add diversity to the number of educational placements for their students, and to potentially facilitate recruit- 
ment of students to rural and remote areas upon graduation. Many studies have demonstrated that students who had previously lived in a rural area, or took part in a rural placement, were more likely to seek employment in rural areas ${ }^{[1-3]}$. Therefore, by providing students with a rural experience, one is potentially making long-lasting contributions to the sustainability of healthcare in the area ${ }^{[4]}$. This paper will identify the principle-based approach and the model that was used in nursing education programming in a rural setting.

\section{Background and significance}

This literature review will outline the potential benefits of building nursing capacity in rural areas with studies primarily from Canada, the United States, and Australia. The Vulnerable Persons Conceptual Framework ${ }^{[5]}$ was utilized to provide a theoretical basis for understanding the concept of health in rural populations and give structure to the review of the literature.

The Framework presents three inter-related concepts including relative risk, health status, and resource availability that together influence the health status of a community ${ }^{[5]}$. Relative risk is described as a population's exposure to risk factors such as lifestyle choices, illness or injury ${ }^{[5]}$. Health status includes population morbidities and mortality, and resource availability ${ }^{[5]}$. The framework suggests that a lack of resources increases relative risk, and that relative risk will influence the health status of a community ${ }^{[5]}$. This framework has been used in several studies to help explain and understand rural populations ${ }^{[6]}$, individuals experiencing posttraumatic stress disorder ${ }^{[7]}$, and other vulnerable populations.

\section{Relative risk}

Major causes of shorter life expectancy in rural areas have been linked to high risks for suicide, motor vehicle accidents, injuries, and chronic obstructive pulmonary disease ${ }^{[8]}$. Eberhardt and Pamuk (2004) ${ }^{[8]}$ found that the death rate from birth to age 24 was 31 percent higher in the most rural areas in the United States compared to those living in the most urban areas. Chronic illnesses have been found to be more prevalent in rural areas than urban across Canada, the United States and Australia. These include certain cancers such as cervical, melanoma and prostate, as well as cardiovascular disease and diabetes ${ }^{[9-11]}$. Infant and child health suffers in rural areas compared to urban. A study of rural Quebec, Canada, found a high rate of teen pregnancy in rural areas ${ }^{[12]}$. Higher infant mortality rates and an increased risk of premature births were found in Pennsylvania, United States ${ }^{[13]}$. Farthing, et al. (2009) found that children exposed to grain bins on farms in rural Saskatchewan, Canada, had more than two times the risk of developing asthma and respiratory issues than children who were not exposed ${ }^{[14]}$.

\section{Health status}

Rural adults and children in Canada, the United States and Australia have all been found to have higher rates of mortality and morbidity ${ }^{[11,15-17]}$. Obesity is more severe in individuals living in rural areas in North America ${ }^{[18]}$. Child obesity of particular concern, as children have been noted to be more inactive than ever before ${ }^{[19,20]}$.

Lifestyle choices, linked to an increased incidence of chronic disease are also more prevalent in rural areas ${ }^{[9]}$. These include alcohol use ${ }^{[8,9,12,21]}$, and smoking ${ }^{[8,12,21]}$.

\section{Resource availability}

The third concept within the framework is resource availability. Lack of access to health care exacerbates already existing health challenges in rural areas. This is most apparent in the lack of specialized services, especially in reproductive and mental health services ${ }^{[22]}$. There is a common lack of screening tests, diagnostic tools, and surgical services available which ultimately delays treatment, and leads to poorer outcomes ${ }^{[11]}$. Often these services are not available as populations are too small to support the associated costs with employing these specialists ${ }^{[16]}$. Mitton, Dionne, Masucci, Wong and Law $(2011)^{[23]}$ found that the further an individual lives from health services, specifically services in an urban center, the worse their health status. 


\section{Rural nursing}

Despite nearly half of the world's population living in rural and remote areas, there is a lack of both physicians and nurses in these areas. Of the health care professional workforce around the world, only 38 percent of nurses and 24 percent of physicians work in rural areas ${ }^{[24]}$. This is even more evident in developed countries such as the United States, where only nine percent of physicians practice in rural areas where 20 percent of the population resides ${ }^{[24]}$. In Canada in 2010, there were 287,344 thousand registered nurses caring for approximately 35 million people in the country ${ }^{[25,26]}$. Only 18 percent of nurses were estimated to be working in rural areas, where 24 percent of the Canadian population lives ${ }^{[24,27]}$. It can therefore be estimated that approximately 51,700 nurses care for 8.4 million people in rural areas in Canada, or a ratio of approximately one nurse to 162 people ${ }^{[25]}$. This ratio is illustrative of significant nursing resource shortages when compared to the remaining 82 percent of nurses who work in urban areas, caring for 76 percent of the population, at a ratio of approximately one nurse to 113 individuals ${ }^{[24,25,27]}$. Most worrisome, is that while the numbers of nurses working in rural areas is on a decline, the population is continuing to grow ${ }^{[27,28]}$. By providing rural placements for nursing students, post-secondary educational facilities have the potential to contribute to building nursing capacity with a goal to ultimately improving the health of rural citizens. A review of the literature demonstrated both positive and negative experiences in placing students in rural areas for educational experiences. Students who participated in rural placements reported a diverse experience, as rural hospitals often treat a wide array of conditions due to a lack of specialty services in the community ${ }^{[1,29]}$. Many students reflected on the supportive atmosphere of rural clinical placements, and the ability to have one on one teaching with mentors ${ }^{[22,29]}$. In a study by Gum (2007), students in rural placements who were from rural areas were able to continue to study in their home town, continue in their employment and family commitments, and gained support from family and friends in a familiar environment ${ }^{[2]}$.

Negative issues include isolation from the educational and urban community, accommodation issues, financial issues related to travelling and accommodation, as well as the inability to continue other commitments from home ${ }^{[2,4,22,29,30]}$. Despite these possible challenges, Elliot et al. (2009) ${ }^{[22]}$ found that negative perceptions of rural placements prior to placement were replaced by overwhelming positive feedback after completion. This study suggests that negative stereotypes should be explored and challenged as much as possible prior to students embarking on placements in the rural area ${ }^{[22]}$.

Nursing student placements also bring benefits to rural agencies and communities. Preceptors in rural areas have been noted to be encouraged by their students, challenged in their own practice, and to have gained new perspectives from their students' current knowledge base ${ }^{[3]}$. Facilities that provide student placements have described a new sense of purpose and identity in being able to share their experiences and expertise with new students ${ }^{[3,31]}$. Rural placements require much time and preparation by educational facilities in order to provide a positive learning experience. These placements require a strong relationship between facility managers and the educational institution. Preceptors must be properly selected in order to provide the most educational placement ${ }^{[32]}$. One must be careful to consider the ability of the placement site to handle numerous students, and avoid overwhelming the placement site ${ }^{[32]}$.

There is a lack of literature reporting improved health outcomes from increasing nursing capacity in rural areas. Perhaps it is too early to report on health outcomes, as the process of increasing capacity has only just begun within the last decade. It can be postulated that an increase in nursing services available in rural areas would contribute to an increase the health status of individuals living in these areas, but this has yet to be reported.

\section{Background}

The purpose of this paper was to describe the community based capacity building model for nursing education and the processes of engagement that developed throughout each component of the model.

\section{The Community Based Capacity Building Model for nursing education}

The University of Saskatchewan is located in the city of Saskatoon in the province of Saskatchewan, Canada. Approximately 35 percent of the population in this prairie province lives in rural settings, which is more than double the number of 
those living in rural areas in other western provinces such as British Columbia, or Alberta ${ }^{[33]}$. The founding of the University of Saskatchewan in 1908 was predicated on a strong relationship between the university and the community it serves. In renewing the University commitment to its history in 2002, President Peter MacKinnon spoke of the University's nurtured connections with its community as its "sense of place" in relation to the province, western Canada, the North, and the Great Plains environments of the world ${ }^{[34]}$.

This commitment to community engagement was reinforced in the University's third integrated plan (IP3) (2012-2016) which highlights the importance of coordinating and strengthening university relationships, enhancing its local and global sense of place, and providing leadership in innovative programming ${ }^{[35]}$. The direction of the IP3 has motivated the College of Nursing to increase our meaningful presence in communities and practice settings beyond our tradition urban base for clinical experiences. The College's relationship with communities has been driven by the following six principles (see Table 1).

Table 1. College of Nursing Guiding Principles ([anonymized for peer review], Unpublished Data)

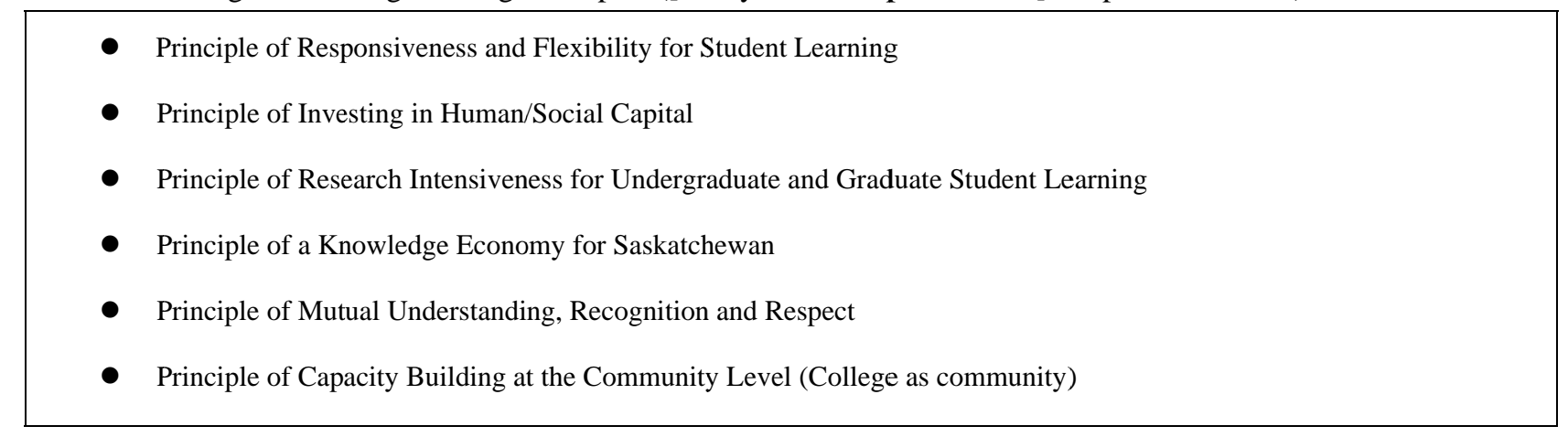

Building on these principles, the Community Based Capacity Building Model for Nursing Education (see Figure 1) was developed. The two most influential principles guiding the Model development were the principle of mutual understanding, recognition, and respect, and the principle of capacity building at the community level.

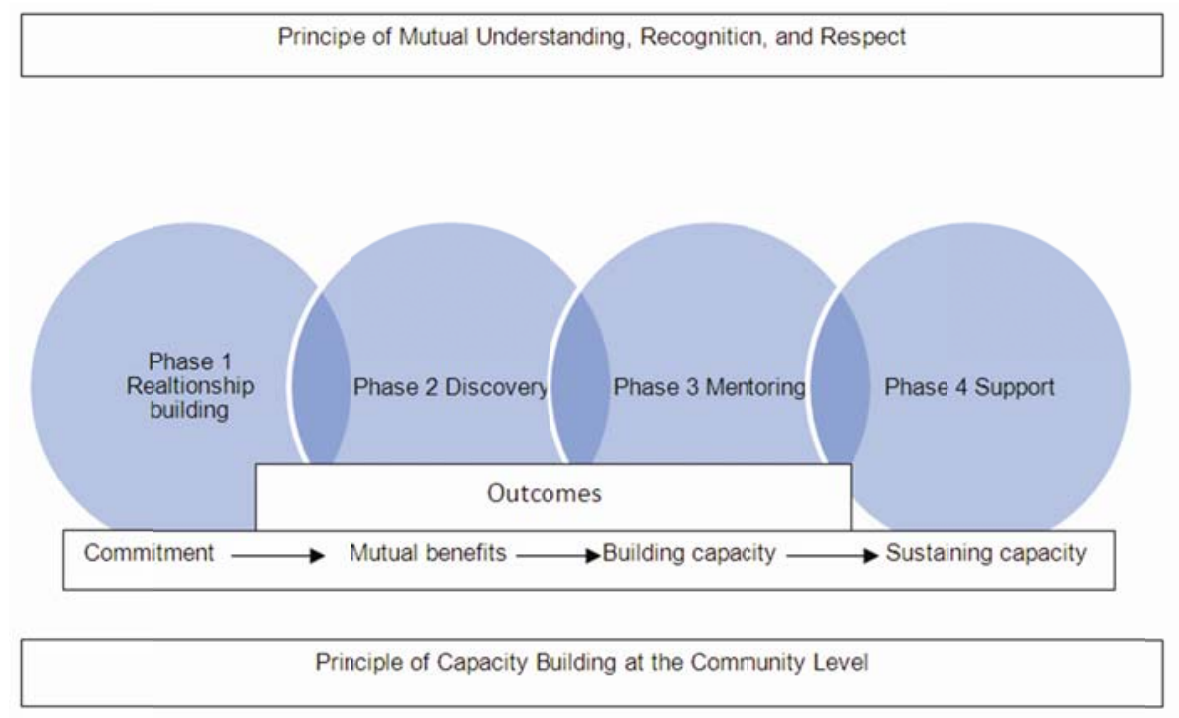

Figure 1. Community Based Capacity Building Model for Nursing Education
Note. This model represents the outcomes obtained through the steps of the capacity building process, and the two principles that guide this collaboration. 


\section{Methods}

The Model focused on four phases in the nursing education capacity building process: relationship building, discovery, mentoring, and support.

Phase 1: Relationship building. The principle of mutual understanding, recognition, and respect, was the foundation for the initial phase of relationship building. The first phase of relationship building involved discussions between individuals from the College of Nursing and rural stakeholders about potential partnerships for nursing education. Stakeholders included individuals from the health region, local community leaders and politicians, local educators and nursing education champions in the nursing community. In the Capacity Building Model, these discussions identified the requirements of the University as well as the capacity of the health region. More specifically, discussions included numbers and levels of students requiring placements and the available capacities needed for the health region to accept nursing students. This foundational phase results in a commitment from both partners to developing clinical opportunities for nursing students in a rural setting.

Phase 2: Discovery. The second phase of the Model, the phase of discovery, involved exchanging knowledge between the faculty and the health region staff. Building on the respect and reciprocity which emerged from the careful attention paid to relationship building in the initial discussions, faculty members and nursing staff explored the possibilities with respect to clinical experiences for students. Nursing staff gained a greater understanding of the curriculum, and of the goals and objectives for these clinical experiences within that curriculum. They gained an understanding of how these experiences would contribute to the development of the foundation competencies required of registered nurses, and how they related to the standards of the profession. Faculty members learnt about the opportunities for experiences for their students, within nursing and in other institution and community-based experiences. The discovery phase resulted in mutual recognition of the importance of theoretical and practice-based experience for students, and created an environment of relational practice where students could learn and grow.

Phase 3: Mentoring. The third phase that of mentoring, occurred during the clinical experience itself. In supporting the student group throughout the experience, the faculty member acted as a role model and mentored the staff nurses in various aspects related to the expectations of clinical teaching and student evaluation. In turn, the staff nurses, experts in the "specialized generalist" approaches of rural nursing, mentored the faculty member in the ways of rural nursing in their particular institution and community.

Phase 4: Support. The final phase of this process is one of ongoing support, and involved the staff nurse moving into a formal teaching role with a group of nursing students. The faculty member supported the nurse in her teaching role with the provision of extensive orientation, consultation, and feedback throughout the clinical experience. The agency acknowledged the change in role for the staff nurse, and provided flexibility in the scheduling of work to accommodate the new role. The agency and the program maintained ongoing supportive relationships based on a recognition of mutual benefit commitment to capacity building.

Traditional evaluative processes and tools such as short surveys and face to face interviews were used to evaluate student responses to the educational experiences in rural settings.

\section{Discussion}

The development and implementation of quality and sustainable clinical experiences in rural settings yielded a model that exemplified a replicable and successful process that may assist other nursing education programs wishing to develop rural nursing placements. When successful, the Capacity Building Model results in a win-win situation for all involved. The intent was that through this process, the nurses from the health regions would become confident and committed to educating nursing students in their facility. 
The approach used in phase 1 (relationship building) was one of mutuality, a different approach to relationships between nursing education and practice than is often seen today. Frequently, nursing education programs simply view practice settings as the provider of clinical placements. There is often little interaction between education and practice except to organize placements and troubleshoot any issues arising in the process ${ }^{[36]}$. Nurses in practice are rarely involved in curriculum development, and report little understanding of the intents of student clinical experience ${ }^{[37]}$. Students often live out this separation between education and practice through experiences of disconnection, and a lack of a sense of belonging ${ }^{[38,39]}$. Educators may view the sole reason for these placements as that of education, and reject or trivialize the importance to the clinical agency of the value of these experiences as opportunities for professional development of their existing staff and recruitment of new graduates.

In this phase 2 or the discovery phase, the planned clinical experience begins to takes shape. Together, the faculty from the university and staff from the rural health region make decisions relating to the site of the clinical placement, the role of the faculty within the facility, and begin to delineate the nature of the mentoring relationship between the nursing faculty and nursing staff. This phase is one of collaboration and engagement of both partners. It is following this phase that a faculty-led clinical placement begins in the rural setting.

In the mentoring phase, the relationships take on more depth. Mentoring relationships produce higher degrees of personal satisfaction, increased career success, development of leadership skills, increased creativity, greater socialization and acceptance, and increased confidence (Rohatinski, 2012, Unpublished Data). Evidence shows that nursing mentorship in rural communities often goes beyond the institutional setting, to assist those being mentored in understanding the culture, patterns of communication, and idiosyncrasies of the specific community (Rohatinski, 2012, Unpublished Data) ${ }^{[40]}$. The intended result of this phase is building capacity. Building capacity results in the deepening and strengthening the relationships between the program and the region, with the ultimate development of a staff nurse who is capable of independently leading a clinical experience with a future group of nursing students in the clinical setting.

The last phase of support results in a quality educational experience for the nursing students. This outcome will meet the requirements of the nursing program, and add the unique dimension of rural health and rural practice to their overall learning experience. This phase ensures the sustaining of the capacity that has been built. It ensures ongoing relationships with the rural practice agency that support its nursing practice needs, honor its importance in the fabric of the local community, recognize the specialized skills of rural nurses, and value the contribution of rural health care agencies to the health of their communities. It fosters the sustained development of rural nurses who can share their valuable skills with nursing students in the clinical learning experience.

Through the implementation of this initiative, several lessons have been learned that warrant sharing with faculty attempting similar program initiatives in rural settings. Firstly, it is imperative for the faculty member from the educational institution to be knowledgeable of the characteristics of rural health and rural practice. Through the implementation of this initiative it was evident that the faculty member who had a background in rural health and rural nursing was sensitive to the uniqueness of the rural setting, and had a level of credibility with students and staff. Secondly, the partnership must be seen to benefit both parties. This outcome evolves through the development of effective relationships which are the foundation for a respectful understanding of each other's requirements and needs. In short, nursing education in rural communities must be a capacity building endeavor based in principles of community development.

There are potential challenges that may occur through the development of this valuable learning opportunity. While the distance from an urban setting is the very nature of a rural clinical practicum, it also results in challenges for students and faculty. There are resource challenges related to travel and accommodations. Exploring creative and affordable options within the rural community is important at the onset of the partnership. Potential isolation from familiar conveniences and supports may be perceived as a sense of loss for students, and it has been found most helpful if students are provided with as much information as possible about the resources (i.e. fitness \& social opportunities, stores) and opportunities in the community or surrounding areas at the onset of their placement ${ }^{[22,29]}$. 
A final lesson learned related to the evaluative process. The results indicated that students had very positive responses to the opportunity to learn in a rural setting. Anecdotally, responses reflected a value in the partnership and the capacity building process between the educational institution and the rural agency. The continued partnership between the university and rural community, which has been three years, is evidence of the sustainability and success of the model.

\section{Limitations}

The main limitation in this study was the lack of a broader and more formalized approach to evaluation. Feedback from nursing staff, other heath personnel, senior administrators, and community representatives and leaders would have provided a more contextualized perspective on the impact of this clinical experience on the rural agency and community. A specific evaluation on the impact of the rural clinical placement on the students' beliefs and knowledge relating to rural practice and rural health would be beneficial. Lastly, it would be most interesting to determine how many of the students in these rural placements practice as registered nurses in rural settings.

\section{Conclusion}

The Vulnerable Persons Conceptual Framework suggests that a lack of resources in the rural setting influences relative risk, or a community's exposure to risk factors, which in turn impacts the health status of rural peoples. Through clinical placements in rural communities, nursing students have the advantage of exploring the depth and breadth of these concepts with experienced rural health professionals. The Capacity Building Process Model provides a framework for partnering with a rural community in the development of clinical placements. Building capacity can be a lengthy process, and one that requires particular attention to the principles of mutual understanding, recognition, and respect. The benefits in doing so, rural communities become intellectual partners with the educational institution, sharing their expertise in, and enthusiasm for rural health and rural nursing.

\section{Acknowledgements and funding}

The authors declare no additional contributions or sources of funding that contributed to the production of this article.

\section{References}

[1] Edwards H, Smith S, Courtney M, Finlayson K, Chapman H. The impact of clinical placement location on nursing students' competence and preparedness for practice. Nurse Educ Today. 2004; 24: 248-255. PMid:15110433 http://dx.doi.org/10.1016/j.nedt.2004.01.003

[2] Gum L. Studying nursing in a rural setting: Are students adequately supported and prepared for rural practice? A pilot study. Rural Remote Health. 2007; 7: 628. PMid:17355184

[3] Page S, Birden H.Twelve tips on rural medical placements: What has worked to make them successful. Med Teach. 2008; 30: 592-596. PMid:18608947 http://dx.doi.org/10.1080/01421590801965129

[4] Van Hofwegen L, Kirkham S, Harwood C. The strength of rural nursing: Implications for undergraduate nursing education. Int J Nurs Educ Scholarsh. 2005; 2: Article 27. http://dx.doi.org/10.2202/1548-923X.1142

[5] Flaskerud J, Winslow B. Conceptualizing vulnerable populations health-related research. Nurs Res. 1998; 47 : 69-78. http://dx.doi.org/10.1097/00006199-199803000-00005

[6] Leight S. The application of a vulnerable populations conceptual model to rural health. Public Health Nurs. 2003; 20 : 440-448. PMid:14629675 http://dx.doi.org/10.1046/j.1525-1446.2003.20604.x

[7] Sumner L, Wong L, Schetter C, Myers H, Rodriguez M. Predictors of posttraumatic stress disorder symptoms among low-income latinas during pregnancy and postpartum. Psychol Trauma. 2012; 4: 196-203. http://dx.doi.org/10.1037/a0023538

[8] Eberhardt M, Pamuk E. The importance of place of residence: Examining health in rural and nonrural areas. Am J Public Health. 2004; 94: 1682-1686. http://dx.doi.org/10.2105/AJPH.94.10.1682

[9] Gamm L, Hutchison L, Dabney B, Dorsey A. Rural healthy people 2010: A companion document to healthy people 2010.2003. http://srph.tamhsc.edu/centers/rhp2010/Volume1.pdf. 
[10] Pohar S, Majumdar S, Johnson J. Health care costs and mortality for Canadian urban and rural patients with diabetes: Population-based trends from 1993-2001. Clin Ther. 2007; 29: 1316-1324. PMid:18036393 http://dx.doi.org/10.1016/j.clinthera.2007.07.001

[11] Smith K, Humphreys J, Wilson M. Addressing the health disadvantage of rural populations: How does epidemiological evidence inform rural heatlh policies and research? Aust J Rural Health. 2008; 16: 56-66. PMid:18318846 http://dx.doi.org/10.1111/j.1440-1584.2008.00953.x

[12] Paluck E, Allerdings M, Kealy K, Dorgan H. Health promotion needs of women living in rural areas: An exploratory study. Can J Rural Med. 2006; 11: 111-116. PMid:16630437

[13] Hillemeier M, Weisman C, Chase G, Dyer A. Individual and community predictors of preterm birth and low birthweight along the rural-urban continuum in central Pennsylvania. J Rural Health. 2007; 23: 42-48. PMid:17300477 http://dx.doi.org/10.1111/j.1748-0361.2006.00066.x

[14] Farthing P, Rennie D, Pahwa P, Janzen B, Dosman J. The association between farming activities and respiratory health in rural school age children. J Agromedicine. 2009; 14: 256-262. PMid:19437286 http://dx.doi.org/10.1080/10599240902799798

[15] Allan J, Ball P, Alston M. Developing sustainable models of rural health care: A community development approach. Rural Remote Health. 2007; 7: 818. PMid:18067401

[16] Jones C, Parker T, Ahearn M, Mishra A, Variyam J. Health status and health care access of farm and rural populations. United States Department of Agriculture (USDA) Economic Research Service. 2009. http://www.ers.usda.gov/media/155453/eib57_1_.pdf

[17] Ziersch A, Baum F, Darmawan I, Kavanagh A, Bentley R. Social capital and health in rural and urban communities in South Australia. Aust N Z J Public Health. 2009; 33: 7-16. PMid:19236353 http://dx.doi.org/10.1111/j.1753-6405.2009.00332.x

[18] Patterson P, Moore C, Probst J, Shinogle J. Obesity and physical inactivity in rural America. J Rural Health. 2004; 20: 151-159. PMid:15085629 http://dx.doi.org/10.1111/j.1748-0361.2004.tb00022.x

[19] Bilinski H, Duggleby W, Rennie D.The meaning of health in rural children: A mixed methods approach. West J Nurs Res. 2010; 32: 949-966. PMid:20634401 http://dx.doi.org/10.1177/0193945910371318

[20] Bilinski H, Rennie D, Duggleby W.Weight status and health characteristics of rural Saskatchewan children. Rural Remote Health. 2011; 11: 1699. PMid:22070419

[21] Mitura V, Bollman R. Health status and behaviours of Canada's youth: A rural-urban comparison. Rural and Small Town Canada Analysis Bulletin. 2004. http://www.statcan.gc.ca/pub/21-006-x/21-006-x2003003-eng.pdf

[22] Elliot T, Bromley T, Chur-Hansen A, Laurence C. Expectations and experiences associated with rural GP placements. Rural Remote Health 2009; 9: 1264. PMid:19968448

[23] Mitton C, Dionne F, Masucci L, Wong S, Law S. Innovations in health service organization and delivery in northern rural and remote regions: A review of the literature. Int J Circumpolar Health. 2011; 70: 460-472. PMid:22030009

[24] World Health Organization. Improving access to health workers in remote and rural areas through improved retention: Global policy recommendations. 2010. http://whqlibdoc.who.int/publications/2010/9789241564014_eng.pdf.

[25] Statistics Canada. Quarterly demographic estimates: July to September 2012. 2012. http://www.statcan.gc.ca/pub/91-002-x/91-002-x2012003-eng.pdf.

[26] Canadian Nurses Association. CRNE bulletin: Statistics on CRNE writers for calender year 2011. 2012. http://www2.cna-aiic.ca/CNA/documents/pdf/publications/CRNE_Bulletin_June_2012_e.pdf.

[27] Macleod M, Kulig J, Stewart N, Pitblado J. The Nature of Nursing Practice in Rural and Remote Canada. 2004. fcrss.org/Migrated/PDF/ResearchReports/OGC/macleod_final.pdf.

[28] Bollman R, Clemenson H. Structure and change in Canada's rural demography: An update to 2006. 2008. http://www.statcan.gc.ca/pub/21-006-x/21-006-x2007007-eng.pdf.

[29] Deaville J, Wynn-Jones J, Hays R, Coventry P, McKinley R, Smith J. Perceptions of UK medical students on rural clinical placements. Rural Remote Health 2009; 9: 1165. PMid:19522554

[30] Neill J, Taylor, K. Undergraduate nursing students' clinical experiences in rural and remote areas: Recruitment implications. Aust J Rural Health. 2002; 10: 239-243. http://dx.doi.org/10.1046/j.1440-1584.2002.00482.x

[31] Shannon S, Walker-Jeffreys M, Newbury J, Cayetano T, Brown K, Petkov J. Rural clinician opinion on being a preceptor. Rural Remote Health. 2006; 6: 490. PMid:16499432

[32] Harwood C, Reimer-Kirkham S, Sawatzky R, Terblanche L, Van Hofwegen L. Innovation in community clinical placements: A Canadian survey. Int J Nurs Edu Scholarsh. 2009; 6: Article 28.

[33] Statistics Canada. Population, urban and rural, by province and territory. 2009. http://www.statcan.gc.ca/tables-tableaux/sum-som/101/cst01/demo62i-eng.htm.

[34] University of Saskatchewan. University of Saskatchewan Strategic Directions: Renewing the Dream. 2002. http://www.usask.ca/ipa/documents/renewing_the_dream.pdf. 
[35] University of Saskatchewanm. Promise and Potential: The Third Integrated Plan 2012-2016. 2012. http://www.usask.ca/plan/documents/Promise\%20and\%20Potential\%20-\%20Full\%20Version.pdf

[36] Berry L. Creating community: Strengthening education and practice partnerships through communities of practice. Int J Nurs Educ Scholarsh. 2011; 8.

[37] Greenwood J. Critique of the graduate nurse: An international perceptive...including commentary by Glen S, Crookes P, and Walter P. Nurse EducToday. 2000; 20: 17-29. PMid:11138212

[38] Hartigan-Rogers J, Amirault M, Cobbett S, Muise-Davis M. Nursing graduates' perceptions of their undergraduate clinical placement. Int J Nurs Educ Scholarsh. 2007; 4: 9.

[39] Levett-Jones T, Lathlean J. Belongingness: A prerequisite for nursing students' clinical learning. Nurse Educ Pract. 2008; 8: 103-111. PMid:18291327 http://dx.doi.org/10.1016/j.nepr.2007.04.003

[40] Mills J, Francis K, Bonner A. Live my work: Rural nurses and their multiple perspectives of self. J Adv Nurs. 2007; 59: 583-590. PMid:17727402 http://dx.doi.org/10.1111/j.1365-2648.2007.04350.x

[41] Canadian Nurses Association. A Nursing Call to Action. 2012.

http://www2.cna-aiic.ca/CNA/documents/pdf/publications/nec/NEC_Report_e. 